
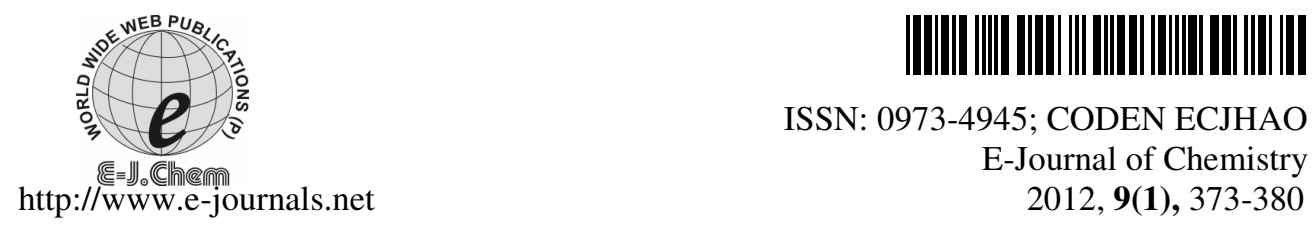

ISSN: 0973-4945; CODEN ECJHAO

E-Journal of Chemistry 2012, 9(1), 373-380

\title{
Optimisation of Graft Copolymerisation of Fibres from Banana Trunk
}

\author{
RICHARD MPON $^{\S}$, MAURICE K. NDIKONTAR $^{\S^{*}}$, \\ HYPPOLITE N. NTEDE ${ }^{\#}$, J. NOAH NGAMVENG ${ }^{\S}$, ALAIN DUFRESNE, \\ OHANDJA AYINA ${ }^{\#}$, EMMANUEL NJUNGAP ${ }^{\S}$ and ABEL TAME ${ }^{\S}$ \\ ${ }^{\S}$ Laboratoire Physico-chimie du Bois \\ Université de Yaoundé 1, Cameroun \\ ${ }^{\#}$ Laboratoroire de Mécanique des Matériaux et de structures \\ Ecole Nationale Supérieure Polytechnique \\ Université de Yaoundé 1, Cameroun \\ Ecole Française de Papeterie et des Industries Graphiques (EFPG-INPG) \\ $\mathrm{UMR}_{\text {CNRS n}}{ }^{\circ}$ 5518, BP 65, F38402 Saint Martin d'Hères Cedex, France \\ mndikontar@yahoo.com
}

Received 8 March 2011; Accepted 30 April 2011

\begin{abstract}
Sheets from banana trunks were opened out and dried for several weeks in air. Pulp was obtained by the nitric acid process with a yield of $37.7 \%$ while fibres were obtained according to the modified standard Japanese method for cellulose in wood for pulp (JIS 8007) with a yield of $65 \%$ with respect to oven dried plant material. Single fibre obtained by the JIS method had an average diameter of $11.0 \mu \mathrm{m}$ and Young's modulus, tensile strength and strain at break-off $7.05 \mathrm{GPa}, 81.7 \mathrm{MPa}$ and $5.2 \%$ respectively. Modification of the fibres was carried out by grafting ethyl acrylate in the presence of ammonium nitrate cerium(IV). Optimisation of the copolymerisation reaction conditions was studied by measuring the rate of conversion, the rate of grafting and the grafting efficiency. The results showed that at low values of ceric ion concentration $(0.04 \mathrm{M})$, at ambient temperature, after three hours and at a concentration of $0.2 \mathrm{M}$ ethyl acrylate, maximum values of the parameters cited were obtained.
\end{abstract}

Keywords: Banana fibres, Grafting, Value-added, Young's modulus, Elongation at fracture

\section{Introduction}

Adding value to the by-products of agricultural activity is very important in research and industry. This importance can only increase when it is noted that nowadays, less than a third of these by-products is used and even far less in the less developed countries. In the vast 
literature on adding value to forestry and agricultural waste, several mechanical, chemical, thermal or a combination of these processes: the bisulphite process, the soda process, the sulfate or Kraft process, the chlorine process and the nitric acid process ${ }^{1}$ have been used for pulping or defribration of which the most popular is the chemithermomechanical method. Also, several plants or plant parts have been explored in the domain of pulping: the cassava stem $^{2}$, the raphia palm frond ${ }^{3}$, the cotton ${ }^{4}$ jute ${ }^{5}$ the banana trunk ${ }^{6}$, etc. Moreover, statistics from the cameroon ministy of agriculture and rural development show that in the period 2001-2004, more than 10 million tons of waste has been thrown away following the banana plantain (Musa sapientum) program. Only the fruit, destined either for local consumption or for export, is used leaving the rest of the plant as waste which, as at now, does not have much use. Locally, the stem is used as mattress or string and packaging for food. Despite its importance, there has not been much reference in literature on the industrial use of this type of waste.

\section{Experimental}

Sheets from banana trunk, which had been properly dried in air, were cut into $0.5 \mathrm{~cm}$ pieces and used for the determination of the cellulose content according to the JIS 8007 method $^{7}$. The cellulose content, $\mathrm{Z}$, was calculated using equation (1):

$$
\mathrm{Z}=\frac{\mathrm{W}}{\mathrm{S}} \times 100
$$

Where $\mathrm{W}$ is the mass of residue obtained and $\mathrm{S}$ the mass of initial oven-dried plant material. The powder $(1.5 \mathrm{~g})$ of banana trunk obtained after alcohol/benzene extraction ${ }^{8}$ was added to $30 \mathrm{~mL}$ of sulphuric acid $(67 \%)$ at room temperature, stirred and stored overnight. It was then diluted with $112.5 \mathrm{~mL}$ of distilled water and boiled under reflux for 5 hours. The insoluble lignin was filtered and washed with distilled water in sintered glass funnel (porosity $\mathrm{n}^{\circ} 4$ ). It was dried in the oven at $110^{\circ} \mathrm{C}$ to a constant mass and then weighed. Measurements were performed in triplicate. The lignin content, L, was calculated according to equations (2) and (3).

$$
\begin{aligned}
& \mathrm{L}=\frac{\mathrm{m}}{\mathrm{M}} \times 100 \\
& \mathrm{M}=\frac{\mathrm{m}_{\mathrm{E}} \times \text { percentage dry wood }}{100}
\end{aligned}
$$

Where $\mathrm{m}$ is the mass of lignin contained in the sintered glass, $\mathrm{M}$ the mass of oven-dried wood and $\mathrm{m}_{\mathrm{E}}$ is the mass of the sample weighed.

\section{Defibration of banana trunk}

The fibres were obtained in the following stages:

- Complete immersion of the sheet pieces in 5\% sodium hydroxide solution for three days in order to remove greases,

- Extraction of sheets in 5\% sodium hydroxide solution by heating at $50{ }^{\circ} \mathrm{C}$ for one hour, Eventual bleaching of the fibres obtained in $0.1 \%$ potassium permanganate and

- $\quad$ Drying of the fibres to a constant mass in the oven at $105^{\circ} \mathrm{C}$.

The yield was also calculated using equation (1).

\section{Pulping of banana trunk}

Dry sheets from the trunk were cut into $1 \mathrm{~cm}$ pieces in order to facilitate penetration of the pulping liquor. In a typical pulping experiment, $60 \mathrm{~g}$ of banana trunk sheet were introduced into a $1 \mathrm{~L}$ flask containing $530 \mathrm{~mL}$ of $7.5 \%$ nitric acid solution with a solid/liquid ratio of 1:9. 
The flask was then heated under reflux at a temperature of $85{ }^{\circ} \mathrm{C}$ in an oil bath for $4 \mathrm{~h}$. The material was then thoroughly washed and strained to remove all traces of acid and then extracted in $530 \mathrm{~mL}$ of $1 \%$ sodium hydroxide solution at $100{ }^{\circ} \mathrm{C}$ for one hour and then washed. Bleaching was carried out by completely immersing the pulp obtained in a $4.7 \%$ sodium hypochlorite solution at ambient temperature for $30 \mathrm{~min}$.

\section{Ethyl acrylate grafting onto banana cellulose pulp}

In a typical grafting trial, $0.3 \mathrm{~g}$ of fibres prepared by the nitric acid method, were dispersed into $43.1 \mathrm{~mL}$ of distilled water. After this, $0.71 \mathrm{~mL}$ of $7 \%$ nitric acid and $1.2 \mathrm{~mL}$ of pure ethyl acrylate were added. The Erlenmeyer was continuously stirred to ensure proper dispersion of the fibres. Finally, $5 \mathrm{~mL}$ of a freshly-prepared $0.3 \mathrm{M}$ cerium ammonium nitrate solution was added to the mixture and the reaction was allowed to proceed for $3 \mathrm{~h}$. The grafted fibres were then abundantly washed with distilled water, filtered and dried to constant weight in an oven at $105{ }^{\circ} \mathrm{C}$. The homopolymer simultaneously formed was extracted from the grafted fibres using dimethyl formamide ${ }^{9}$ under reflux in a soxhlet for $48 \mathrm{~h}$. The fibres were then thoroughly washed with acetone, filtered and dried to constant weight in an oven at $105{ }^{\circ} \mathrm{C}$. The grafting parameters were calculated using the following equations:

$$
\begin{array}{r}
\% \text { conversion }=\frac{\mathrm{C}-\mathrm{A}}{\mathrm{B}} \times 100 \\
\% \text { graft }=\frac{\mathrm{D}-\mathrm{A}}{\mathrm{A}} \times 100 \\
\text { graft efficiency }=\frac{\mathrm{D}-\mathrm{A}}{\mathrm{C}-\mathrm{A}} \times 100
\end{array}
$$

Where A, B, C and D are the mass of ungrafted fibres, mass of monomer, mass of unextracted copolymer and mass of extracted copolymer, respectively.

\section{Infrared spectroscopy}

Infrared (IR) spectroscopy was used to confirm the grafting reaction. Powder of the ungrafted and grafted fibres were obtained in Retsch mill 82508 001(35 mesh) and IR spectra were recorded using an alpha-p Brucker spectrometer in the solid state.

\section{Geometrical characteristics of the fibres}

To obtain the diameter, a single fibre bundle from those obtained by the modified JIS method was used. It was tied to a $25 \times 25 \mathrm{~mm}$ square board and then observed under an OLYMPUS microscope using ordinary white light. Its diameter was measured using a graduated slide. 10 replicates were made.

\section{Mechanical properties}

A single fibre like the one used above was clamped into the jaws of a MECMESIN 04-1006-02 vertical traction instrument coupled to a computer. The sample was then subjected to a tensile strength test at room temperature with a cross head speed of $0.2 \mathrm{~mm} / \mathrm{s}$ up to breaking point. Software data plot captured the tensile force $(\mathrm{N})$ and elongation $(\mathrm{mm})$ data from the traction instrument in the form of a table of numerical results as a function of the diameter of the fibre. Tensile stress and strain were determined and a graph was drawn in excel software its linear regression was used to determine the slope and hence the Young's modulus (E) of the sample. The last values of the columns indicate the tensile strength $\left(\sigma_{\max }\right)$ and strain at break $\left(\varepsilon_{\mathrm{R}}\right) .10$ samples were tested. 


\section{Results and Discussion}

\section{Cellulose and lignin contents}

The cellulose and lignin contents in the banana trunk were found to be averagely 70.0 and $13.7 \%$ respectively. These results agree with earlier studies which classify banana stem in the group of plants which have a high cellulose $(60-80 \%)$ and lignin content $(\geq 5)^{6,10}$. The difference in lignin content with respect to earlier results ${ }^{10}$ is probably due to the method of determination used or the species of banana.

\section{Pulping and defibration of the banana stem}

In this study and as explained earlier, fibres were obtained using a 'hard method' (nitric acid process) $^{11}$ and a 'gentle method' (the modified JIS P 8007 method) ${ }^{7}$. From these two methods, yields of $32.7 \%$ and $65 \%$ were obtained for pulping and defibration respectively calculated on the basis of oven-dried initial plant material. This difference in yield could be expected because the percentage recovery of cellulose from plant material depends on the method used. Moreover, the 'hard method' would destroy the cellulose fibrils in the plant to produce pulp while the 'gentle method' would preserve them to produce fibre bundles.

Bleaching was performed using potassium permanganate which leads to a decrease in mass attributed to the elimination of lignin from the fibres in order to give them the characteristic white colour. It is obvious that there is more lignin retained in the fibres obtained by the 'gentle method'.

\section{Physical parameters}

The dimensions of a fibre define, to a certain extent, its potential use. The average diameter of the fibres obtained by the 'gentle method' was $d=11.0 \mu \mathrm{m}(\mathrm{S}=0.206)$. This fibre can be classified as long since its aspect ratio (L/d) is more than 100 (length of fibre used $\sim 25 \mathrm{~mm}$ ); below 100, it would have been considered as short ${ }^{1}$.

\section{Mechanical properties of unbleached fibres}

The mechanical properties of long fibres obtained by the modified JIS P 8007 method are reported in Table 1. By a linear regression analysis, the following results were retained as parameters for banana fibres: $\mathrm{E}=7.05 \mathrm{GPa}, \sigma_{\max }=81.7 \mathrm{MPa}$ and $\varepsilon=5.2 \%$ (at $5 \%$ level significance).

Table 1. Mechanical properties of banana fibres

\begin{tabular}{cccc}
\hline Fibre sample & $\mathrm{E}(\mathrm{MPa})$ & $\delta_{\max }(\mathrm{MPa})$ & $\varepsilon_{\mathrm{R}}, \%$ \\
\hline $\mathrm{T}_{1}$ & 5911.6 & 104.15 & 6 \\
$\mathrm{~T}_{2}$ & 7102.0 & 114.59 & 4 \\
$\mathrm{~T}_{3}$ & 3496.3 & 25.80 & 8 \\
$\mathrm{~T}_{4}$ & 5183.1 & 34.63 & 4 \\
$\mathrm{~T}_{5}$ & 9139.8 & 138.96 & 4 \\
$\mathrm{~T}_{6}$ & 6367.0 & 114.59 & 6 \\
$\mathrm{~T}_{7}$ & 7531.7 & 73.34 & 4 \\
$\mathrm{~T}_{8}$ & 11742.0 & 92.84 & 4 \\
$\mathrm{~T}_{9}$ & 8359.4 & 59.33 & 4 \\
$\mathrm{~T}_{10}$ & 4634.8 & 78.69 & 8 \\
standard deviation & 642.4 & 11.6 & 1.7 \\
confidence interval & $6626.1-7482.6$ & $73.9-89.4$ & $4.1-6.3$ \\
\hline
\end{tabular}


Banana belongs to the group of plants with a high lignin content ${ }^{12}$ which include, among other, jute, sisal, bamboo, bagasse and cassava. Moreover, there is a correlation between mechanical properties and cellulose content. As much as the parameters measured above depend on the defibration method used and the plant part concerned; they also depend on the zone and the period of harvest. Moreover, the variability of the values obtained could be related to either the local voluminal rate of the fibre or the conditions of the experiment or both $^{13}$. Others studies are now proposing a new method to resolve this variability ${ }^{14}$.

\section{Grafting of ethyl acrylate onto banana fibres}

The grafting evidence is shown in the IR spectra reported in Figure 1 by the appearance of the stretching absorbance band of the carbonyl group on the grafted fibre spectrum $\left(1710-1725 \mathrm{~cm}^{-1}\right)$ and the decrease of the absorbance band in $3600-3100 \mathrm{~cm}^{-1}$ and $1017-1138 \mathrm{~cm}^{-1}$ zone which correspond to the decrease of the $(\mathrm{O}-\mathrm{H})$ and $(\mathrm{C}-\mathrm{O})$ bonds, respectively. This carbonyl absorbance band (which does not exist on the ungrafted fibre spectrum) can be attributed to the grafting of ethyl acrylate on the fibre.

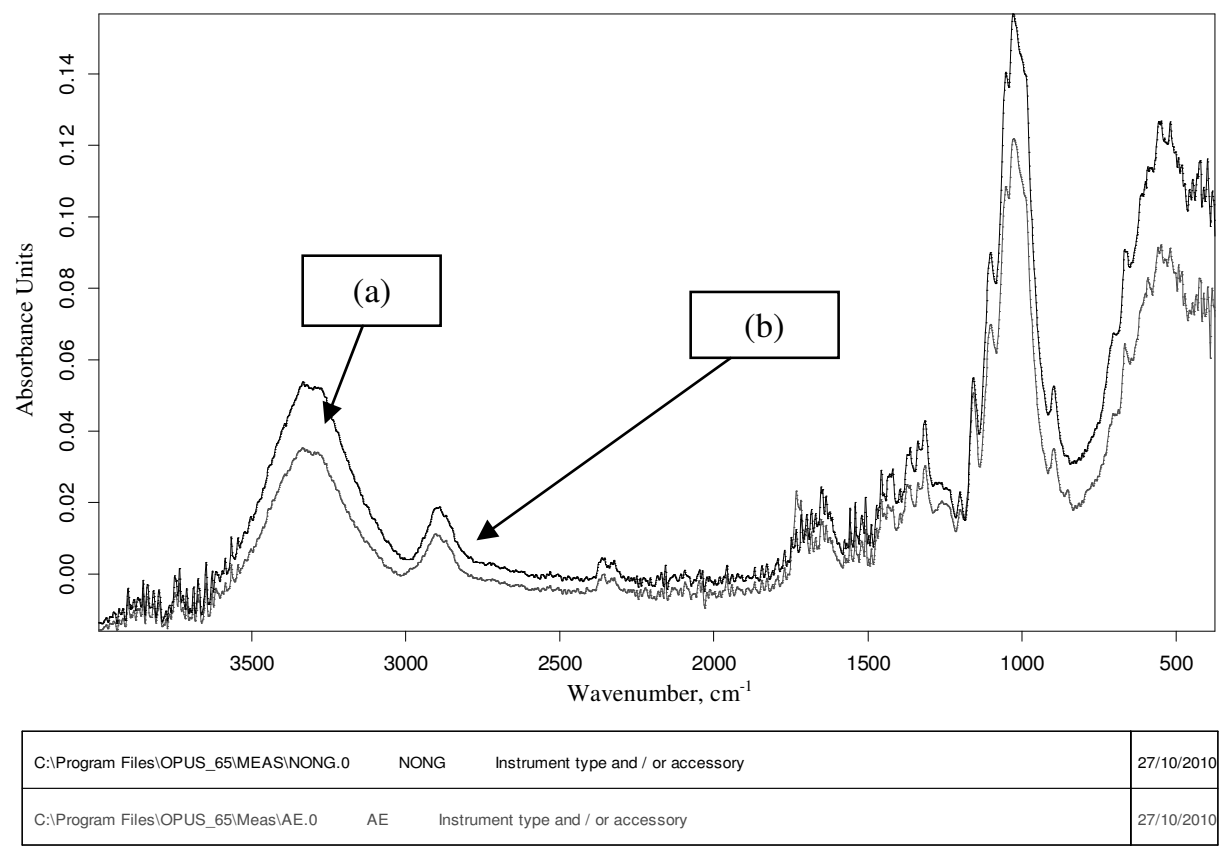

Figure 1. IR spectra of non-grafted fibres (a) and grafted fibres (b)

Chemical grafting or copolymerisation reaction is influenced by the monomer concentration, initiator concentration, reaction time and temperature. By modifying these parameters, the conditions of copolymerisation can be optimised in order to improve the grafting efficiency. In this study, the parameters calculated were the percentage conversion of the monomer, the percentage grafting and the efficiency of the grafting, following the measurement of the influence of the variation of the concentrations of the monomer ethyl acrylate and the initiator cerium(IV) ion. The values of the parameters calculated for the influence of ethyl acrylate concentration (an average of 3 replications) are represented in Figures 2 and 3 respectively for unbleached and bleached fibres. The results of the variation of the concentration of cerium(IV) are represented in Figures 4 and 5 respectively for unbleached and bleached fibres. 


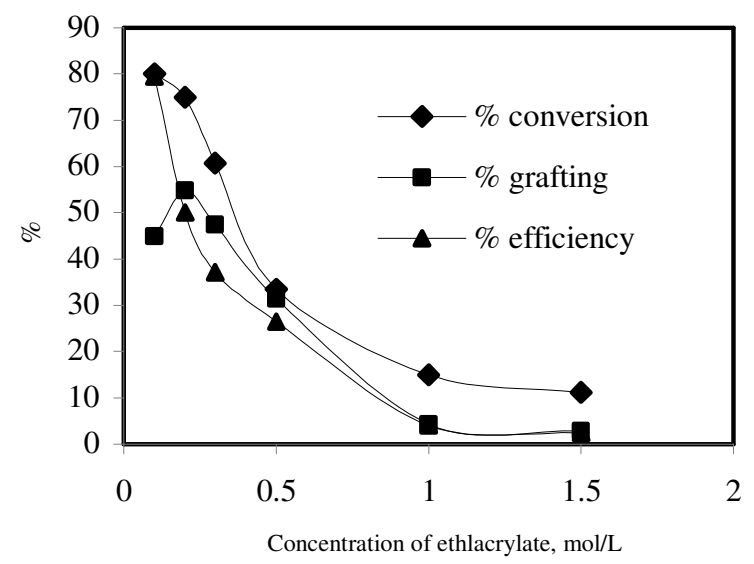

Figure 2. Influence of concentration of the ethyl acrylate on the grafting of unbleached fibres

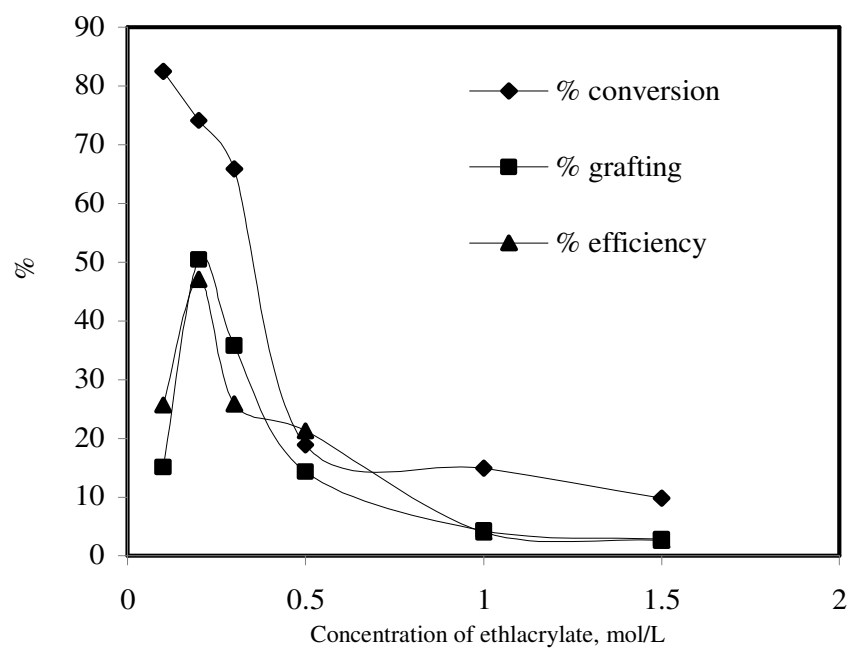

Figure 3. Influence of concentration of the ethyl acrylate on the grafting of bleached fibres

First of all, it should be noted that intermittent or continuous stirring of the reaction medium did not make any difference in the results obtained. However, no stirring at all favoured the formation of homopolymer: the initiator did not have full access to the fibre surface and therefore reacted only with the monomer.

Percentage grafting was higher at lower monomer concentrations while homopolymer formation was favoured at higher monomer concentrations. This is in agreement with the result of Kokta et al. ${ }^{15}$ for whom too many monomers molecules competed for a very small number of radicals. The highest monomer conversion rate ( 92\%) occurred for bleached fibres. This could be explained by the fact that the initiator could have been used up for the radical oxidation of hydroxyl and carbonyl groups on lignin in unbleached fibres.

It is also observed that there is a global decrease of parameters after extrema. Other workers ${ }^{16-19}$ explained this decrease by the fact that after the extrema, the number of radicals produced by the initiator $\mathrm{Ce}^{4+}$ ion and which leads to effective grafting is smaller than the number of primary radicals or the number of growing chains stabilised by the termination 
reaction which involves the ceric ion. The ion therefore acts like an inhibitor of copolymerisation when its concentration becomes significant. In addition, the rapidly increasing initial stage observed could be ascribed to the reaction of $\mathrm{Ce}^{4+}$ with the easily reacting portion of the cellulose chain. This is followed by the slower reaction which corresponds to the decreasing stage (Figures 2 and 3) or plateau (Figures 4 and 5). The decrease of the extrema values of the efficiency curve when passing from Figure 1 to Figure 2 may be ascribed to a decrease in reacting sites on the cellulose chain. Figure 4 shows a rapidly increasing step up to $0.04 \mathrm{M}$ followed by a plateau between 0.04 and $0.055 \mathrm{M}$ and a decreasing stage corresponding respectively to the copolymerisation reaction, competition between copolymerisation and homopolymerisation and homopolymerisation reaction for all curves. Figure 5 shows a different sequence in the same interval of concentration; the maximum would be at concentration lower than $0.03 \mathrm{M}$ ethyl acrylate. Figure 4 exhibits a maximum at $0.2 \mathrm{M}$ either for percentage grafting or grafting efficiency. This disparity can be explained by the fact that bleaching cellulose fibre renders it directly accessible to the monomer, which is not the case in unbleached fibre still held together by lignin.

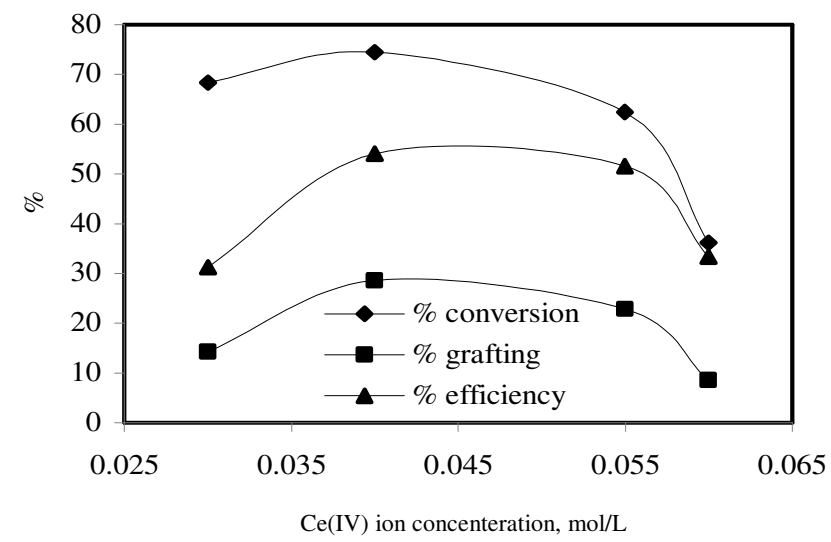

Figure 4. Influence of concentration of the ceric ion on the grafting of not bleached fibres

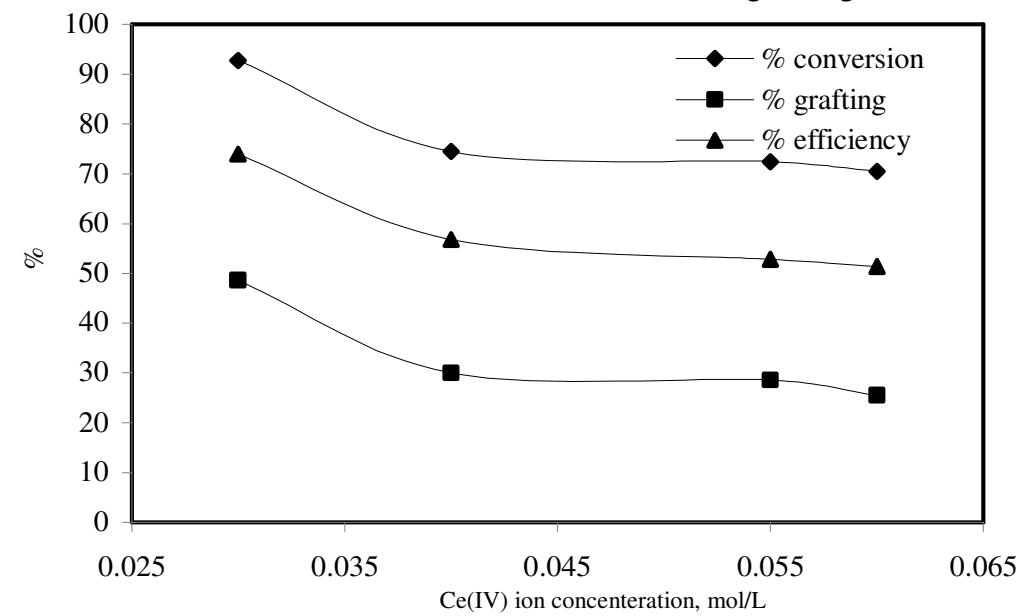

Figure 5. Influence of concentration of the ceric ion on the grafting of bleached fibres 


\section{Conclusion}

The fibre from banana trunk (70.0\% cellulose and $13.7 \%$ lignin) was isolated from the other components which are lignin, hemicelluloses, waxes, minerals, etc. The fibres, richer in cellulose and then bleached, were studied under the ordinary microscope and the vertical tensile machine, respectively, to measure their diameter $(\mathrm{d}=11.0 \mu \mathrm{m})$ and mechanical properties $\left(\mathrm{E}=7.05 \mathrm{GPa}, \sigma_{\max }=81.7 \mathrm{MPa}\right.$ and $\left.\varepsilon=5.2 \%\right)$. Subsequently, bleached and unbleached fibres were subjected to a grafting chemical reaction using ethyl acrylate in order to improve its hydrophilicity hence considering it like a raw material for the textile industry. The highest conversion rate $(\sim 92 \%)$ was obtained in the case of beached fibres and extrema at $0.04 \mathrm{M}$ for all curves in the effect of $\mathrm{Ce}^{4+}$ concentration on the grafting reaction while only grafting percentage and efficiency presented extrema at $0.2 \mathrm{M}$ on the effect of monomer. Further work will study, not only the coating, but also the compatibility of the banana fibre with hydrophobic synthetics polymers.

\section{Acknowledgment}

The authors are grateful to the Aires-Sud program for financial assistance to the two laboratories (MANIF project grant $n^{\circ}$ AIRES-Sud 7202) and to the University of Yaoundé I for providing the infrastructure for carrying out this work.

\section{References}

1 Ndikontar M K, Greffage de la cellulose extraite du manioc Applications de la cellulose greffée. Thèse de doctorat de $3^{\text {rd }}$ cycle, Université de Yaoundé, 1991, 1-60.

2 Ngamveng J N and Ndikontar M K, Cellul Chem Technol., 1990, 24(4), 523-530.

3 Ngamveng J N, Ann Fac Sc Chem., 1986, 1(1-2), 33.

$4 \quad$ Zeronian S H and Ryu H S, J Appl Polym Sci., 1987, 33, 2587-2604.

$5 \quad$ Blezki A K, Reihmane S and Gassan J J Appl Polm Sci., 1996, 59, 1329-1336.

6 Eloundou J P, Ntede N H, Mbang T, Ayina O, Issartel N, Gérard J F and Pascaut J P, Communication to the World Polymer Congress Macro Paris., 4-9 July 2004.

7 Japanese Standards Association, Testing Method for Cellulose in Wood for Pulp JIS P 8007, Hohbunsha Co Ltd., Tokyo 1976.

8 Technical Association of the Pulp and Paper Industry, Tappi Test Methods, (T 222 om-88), vol 1, Atlanta, 1989.

9 Lepoutre P, Hui S H and Roberson A A, J Appl Polym Sci., 1973, 17, 3143-3156.

10 Jain S, Kumar R and Jindal U C, J Meter Sci., 1992, 27, 4598.

11 Biyani B P, Garbatsevich S N and Lorey F W, Tappi., 1967, 50(1), 87-91.

12 Silva G G, De Souza D A, Machado J C and Hourston D J, J Appl Polym Sci., 2000, 76, 1197-1206.

13 Poliâne C, Vivet A, Momayez L, Doudou B B and Ayachi M et Chen J, Comptes Rendus des JNC, 2009, 16, 7.

14 Mir A, Zitoune R and Collombert F et Bezzazi B, Comptes Rendus des JNC., 2009, 16, 10.

15 Kokta V, Lo R C and Daneault C, J Appl Polym Sci Chem Ed., 1982, 25, 272-281.

16 Ogiwara Y and Kubota H, J Polym Sci., 1967, 5, 2791.

17 Hebeish A, Kantouch A and El-Rafie M H, J Appl Polym Sci., 1971, 15, 11.

18 Varma D S and Narasimham V, J Appl Polym Sci., 1972, 16, 3325.

19 Cumberbirch R J E and Holker J R, J Soc Dyers Colour, 1966, 82. 


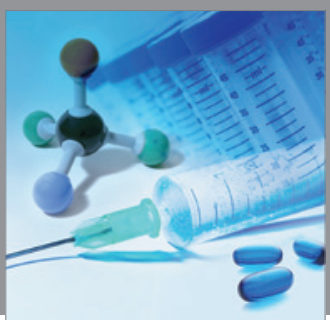

International Journal of

Medicinal Chemistry

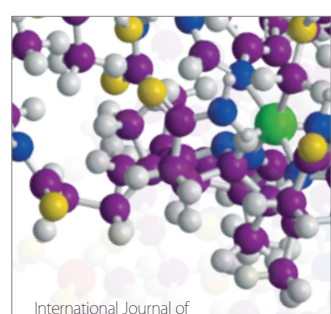

Carbohydrate Chemistry

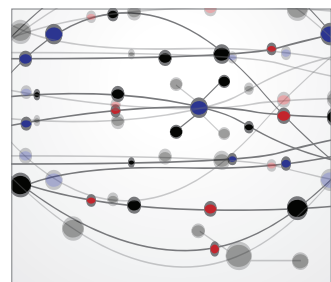

The Scientific World Journal
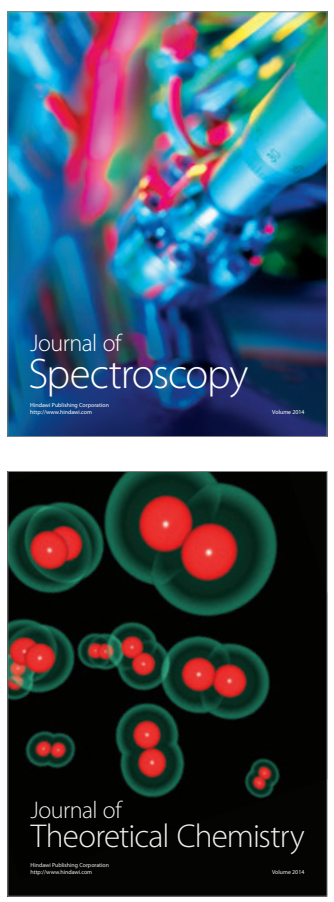
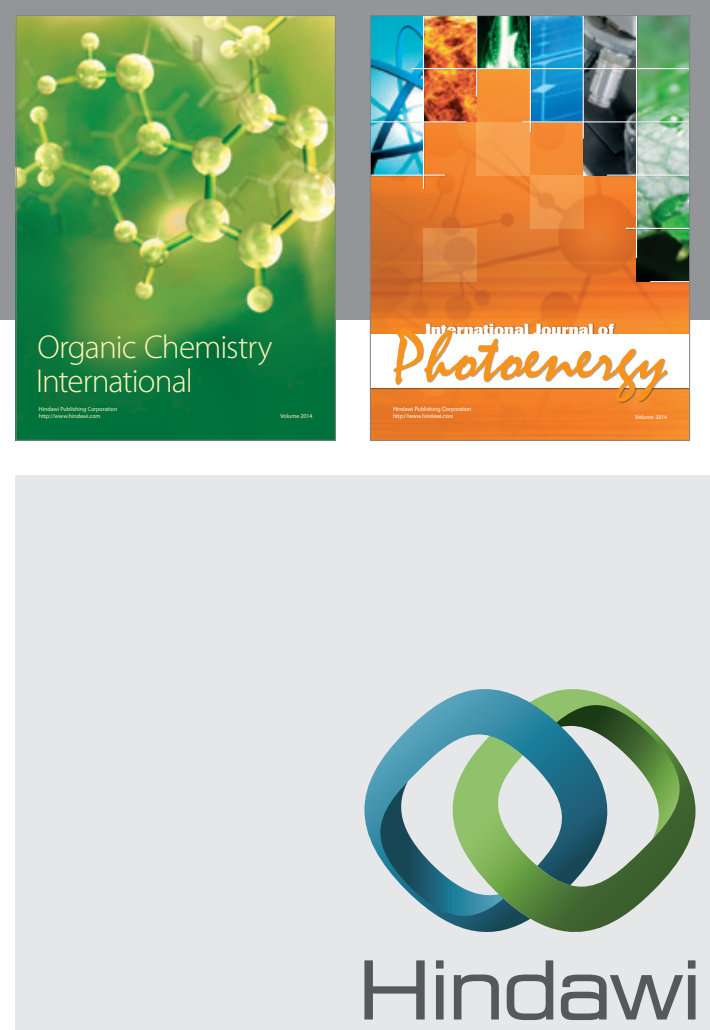

Submit your manuscripts at

http://www.hindawi.com
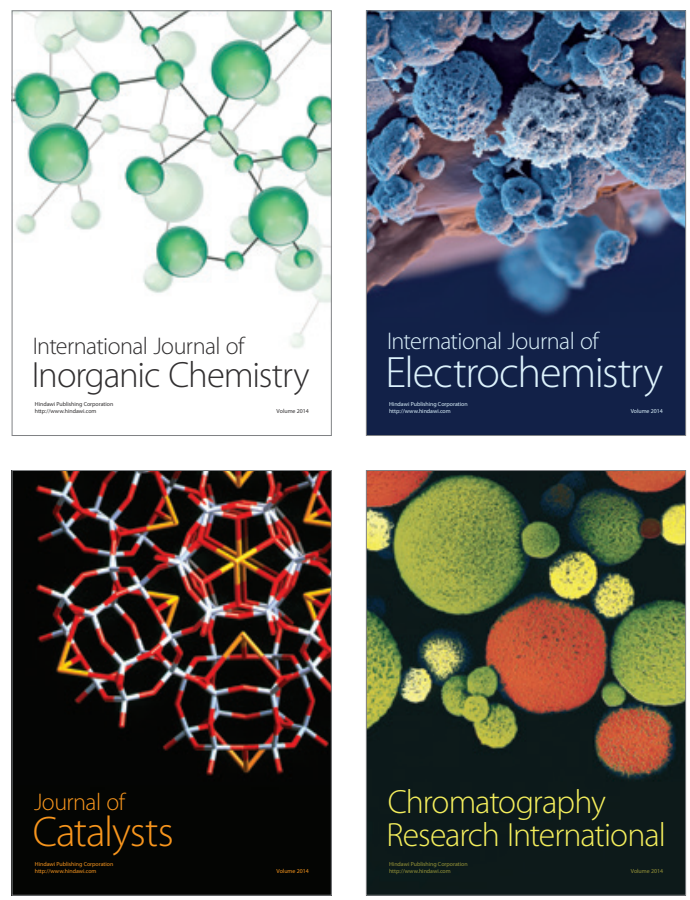
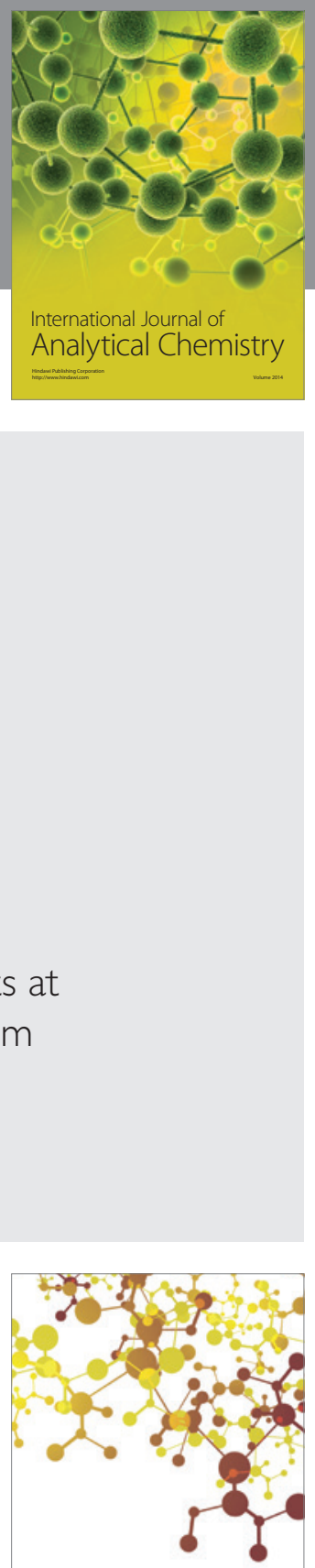

Journal of

Applied Chemistry
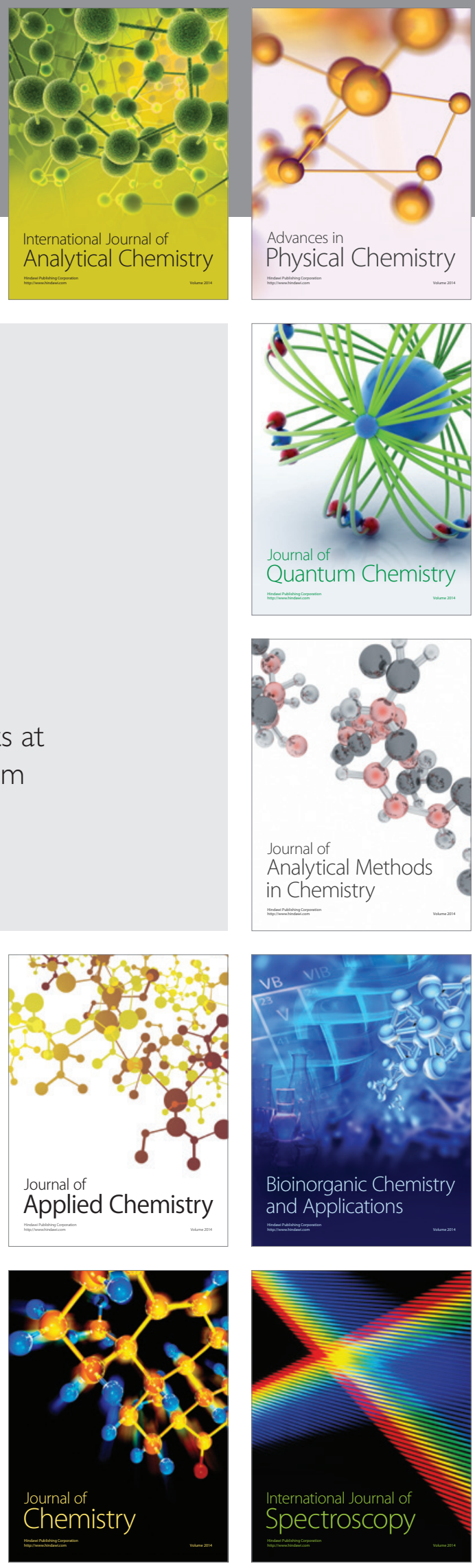